Supplement of Biogeosciences Discuss., 12, 7537-7575, 2015

http://www.biogeosciences-discuss.net/12/7537/2015/

doi:10.5194/bgd-12-7537-2015-supplement

(C) Author(s) 2015. CC Attribution 3.0 License.

(c) (i)

Supplement of

\title{
Parameterization of biogeochemical sediment-water fluxes using in-situ measurements and a steady-state diagenetic model
}

\section{A. Laurent et al.}

Correspondence to: A. Laurent (arnaud.laurent@dal.ca)

The copyright of individual parts of the supplement might differ from the CC-BY 3.0 licence. 

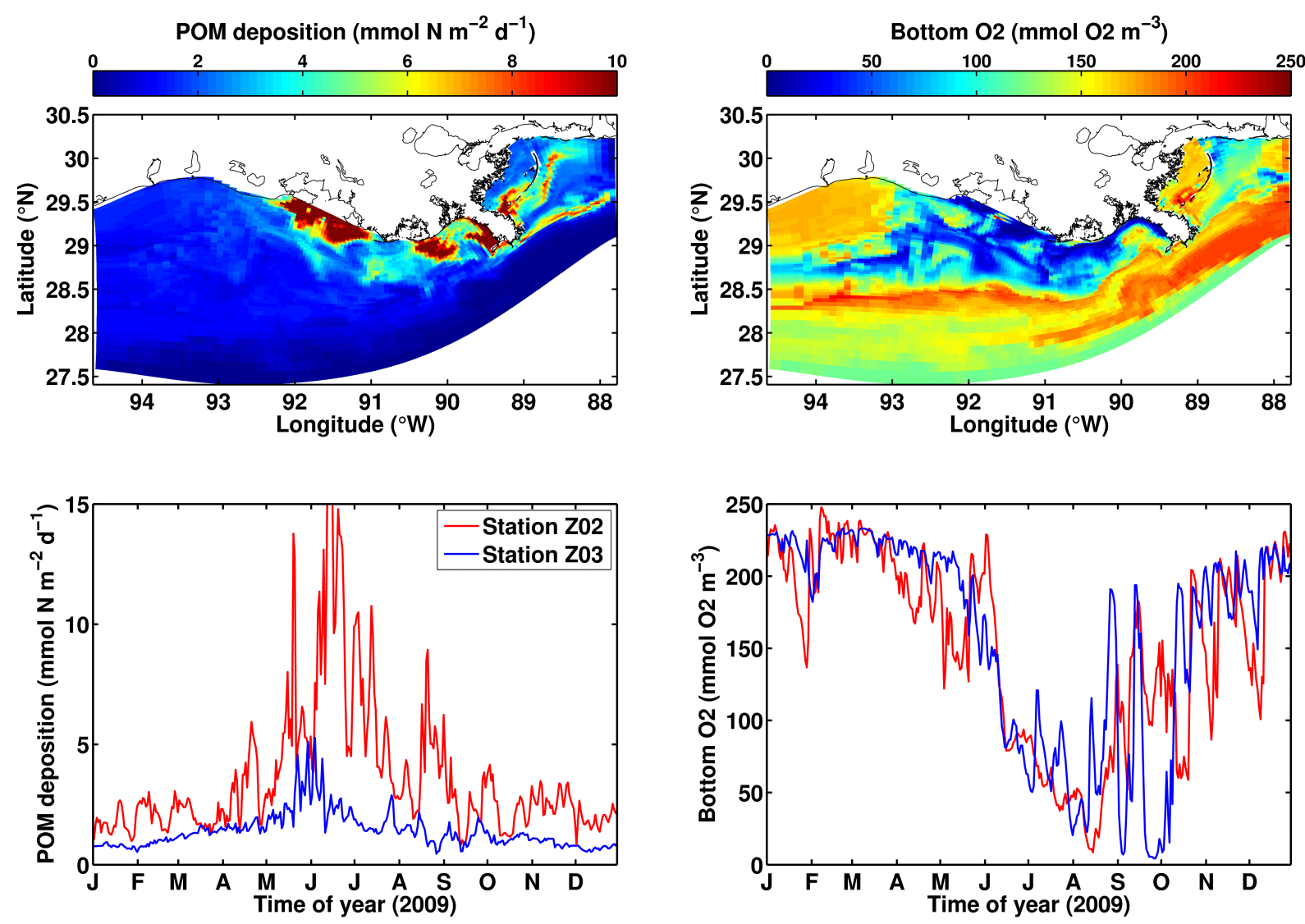

Figure S1. Spatial (top) and temporal (bottom) POM depositional flux and bottom water

$\mathrm{O}_{2}$ concentration in the biogeochemical circulation model. The upper panels represent a snapshot of bottom water conditions on July $20^{\text {th }}, 2009$. This dataset is used to force the diagenetic model in the meta-modeling procedure (Section 2.2) and to compare the meta-model and H\&D parameterizations (Figure S2). 


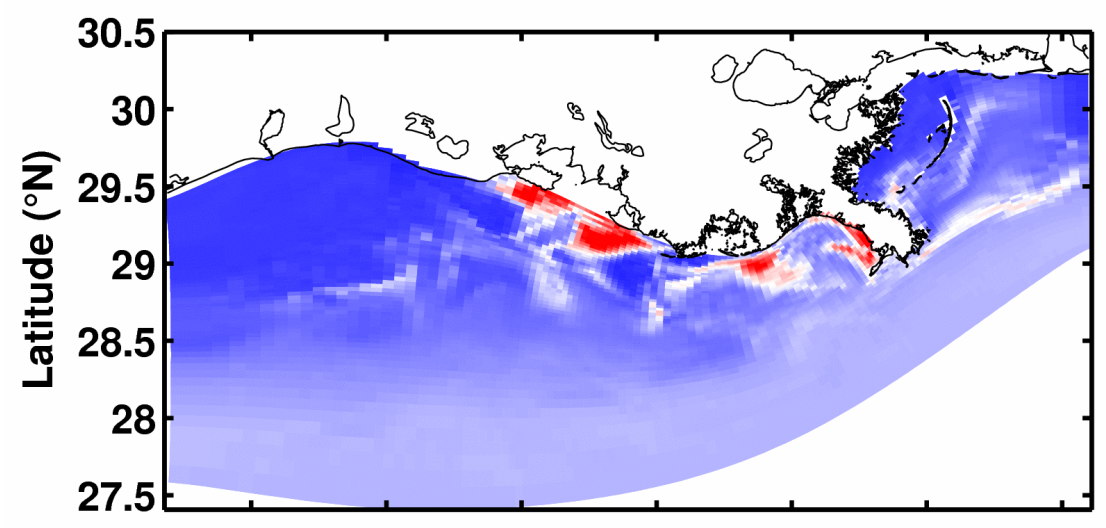

Change in 02 flux (mmol $02 \mathrm{~m}^{-2} \mathrm{~d}^{-1}$ )

\begin{tabular}{|c|c|c|c|c|c|c|c|c|c|}
\hline-50 & -40 & -30 & -20 & -10 & 0 & 10 & 20 & 30 & 40 \\
\hline-5 & -4 & -3 & -2 & -1 & 0 & 1 & 2 & 3 & 4 \\
\hline
\end{tabular}

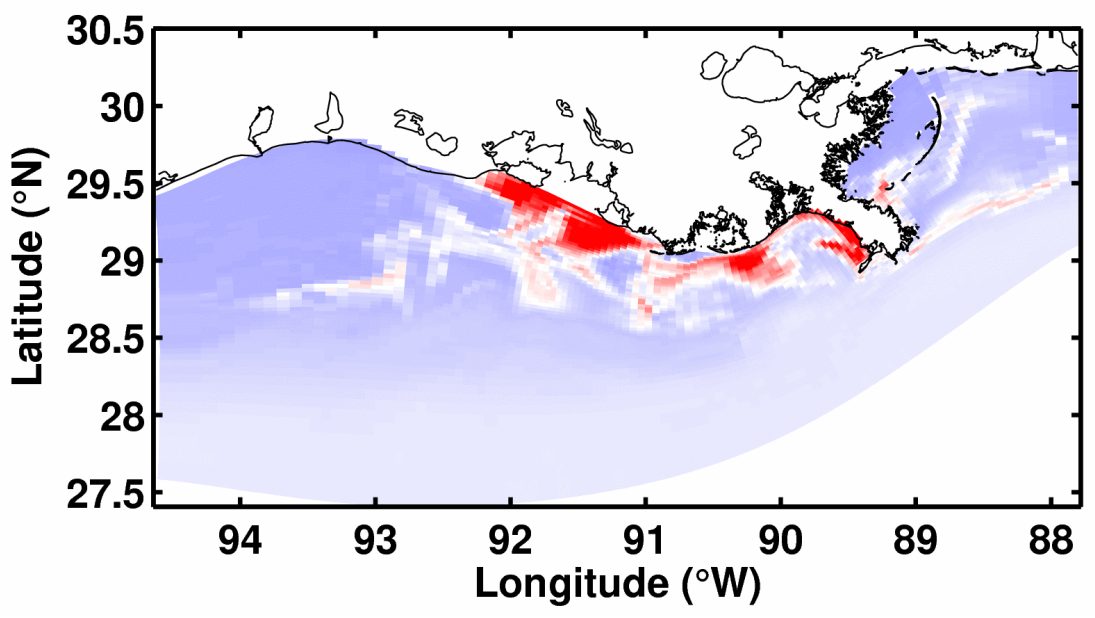

Figure S2. Difference between parameterized oxygen (top panel) and ammonium (bottom panel) fluxes during the LUMCON cruise in 2009 and fluxes simulated with the H\&D parameterization. 